\title{
ARTICLE
}

\section{Monitoring Mineral-Associated Organic Matter in Tropical Pastures using Near Infrared Spectroscopy}

\author{
Felipe Bachion de Santana1 ${ }^{1 D}$, André Marcelo de Souza2*iD $₫$, Fabiano de Carvalho \\ Balieiro ${ }^{2}$ iD, Mirelly Mioranza ${ }^{3}$ iD, Renato Aragão Ribeiro Rodrigues ${ }^{2}$ iD, Ronei Jesus Poppi ${ }^{1}$ (iD† \\ ${ }^{1}$ Instituto de Química, Universidade Estadual de Campinas, Caixa Postal 6154, CEP 13084-971, Campinas, SP, \\ Brazil \\ ${ }^{2}$ Empresa Brasileira de Pesquisa Agropecuária (Embrapa Solos), R. Jardim Botânico, 1024, Rio de Janeiro, RJ, \\ CEP 22460-000, Brazil \\ ${ }^{3}$ Universidade Federal Fluminense, CEP 24020-141, Niterói, RJ, Brazil \\ † In memoriam (1961 - 2020)
}

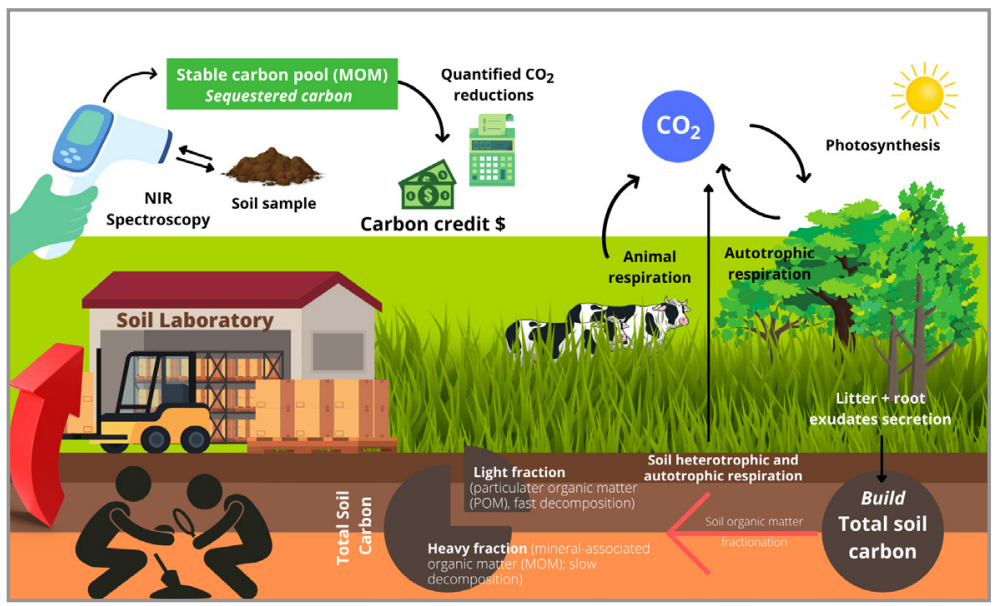

In order to confirm that the mitigation of greenhouse gas emissions could indeed be achieved by farmers, determinations of soil organic carbon (SOC) in total and stabilized fractions are essential, proving the effectiveness of the sustainable practices adopted by the farmer. In this sense, this study proposes an analytical methodology based on near infrared spectroscopy (NIRS) and partial least squares regression (PLSR) as an alternative for the measurement of stabilized and total soil organic carbon (SOC) in agricultural production systems. A set of 122 samples of four different land uses were sampled and physically fractionated. Total organic carbon for both fractions (mineral-associated stable fraction and particulated organic matter - labile fraction) were determined by the dry combustion method. In order to eliminate the extra step regarding soil fractionation to determine the stabilized SOC content, this study investigated different strategies to build the regression model based on partial least squares regression for the determination of the stabilized SOC from the total soil fraction. Two strategies presented the same accuracy as the reference method used to determine the stabilized SOC content in stabilized fraction, with root mean square error in validation of $1.47 \mathrm{~g} / \mathrm{dm}^{3}$. These results indicate that both strategies proposed can determine simultaneously the total and stabilized SOC from the total soil fraction, thus eliminating the fractionation phase.

Cite: de Santana, F. B.; de Souza, A. M.; Balieiro, F. C.; Mioranza, M.; Rodrigues, R. A. R.; Poppi, R. J. Monitoring MineralAssociated Organic Matter in Tropical Pastures using Near Infrared Spectroscopy. Braz. J. Anal. Chem., 2021, 8 (32), pp 78-90. doi: http://dx.doi.org/10.30744/brjac.2179-3425.AR-10-2021 
Keywords: soil stabilized fraction; soil organic carbon; near infrared spectroscopy; multivariate calibration

\section{INTRODUCTION}

The ABC Plan (Agricultura de Baixa Emissão de Carbono - Low Carbon Agriculture) is part of a strategy adopted by the Brazilian Government for reducing greenhouse gas (GHG) emissions from agriculture. This policy aims to encourage the farmers to adopt technologies and sustainable production systems to ensure GHG emissions reduction [1]. The main goals of the ABC Plan are to expand the integrated crop-livestockforest systems to 4 million hectares, and the area with zero-tillage to 8 million ha, rehabilitate 15 million ha of degraded pastures, planting more 3 million ha of forests and increase the adoption of biological nitrogen fixation in more 5.5 million ha by 2020 .

In order to attest that the mitigation of GHG emissions could indeed be achieved by farmers, soil organic carbon (SOC) testing and monitoring would become an essential part of the process to prove the effectiveness of the adoption of such sustainable practices that support the program. By this way, the demand for SOC analysis would significantly increase and an analytical methodology to measure the additionality of SOC sequestration of any technology or project adopted has become a key factor for the implementation of ABC Plan.

Soil organic matter (SOM) has been characterized by chemical and physical fractionation. Both tries to minimize the heterogeneity of the soil organic components in terms of composition, availability to soil biota and environmental functions [2]. The choice of fractionation methods depends on the study objectives. Chemical fractionation is based in different solubility of humic substances to alkaline and acid solutions and normally is used to chemical characterization of specific organic soil compounds or fraction (mainly humic acid fraction) and land use impacts, while physical fractionation is used to quantify and describe the compartments of SOM linked to nutrient cycling and C sequestration [2,3]. The relationship between SOM and soil physical constituents could be studied at two level of organization: SOM associated with mineral particles (sand, silt, and clay) - particle-size fractionation and SOM associated with macro and microaggregates - aggregate fractionation approach [4].

In the tropics, despite the higher SOM turnover, the particulate organic matter (POM) pools (more labile) make up a relatively small proportion of SOM in comparison to organo-mineral (clay in special) fraction and the mean residence time, or the half-life of $C$ (in years) increase as fraction size decreases [4]. In other words, the lower C-turnover of mineral-organic associated matter (clay + silt associated fraction) comprises the most stable compartment of soil.

Considering SOC analysis for fertility purposes, the standard sample preparation procedures that have been practiced for decades (based on Walkley-Black or dry combustion) are able to assess the bulk organic carbon in the soil sample, without considering the proportion of these labile and stable fractions $[5,6]$. This means that new steps regarding to soil fractionation are necessary to determine the labile and stable C.

However, all reference methods to fractionate soil organic carbon are cost intensive and laborious. The combination of an extra soil fractionation step with traditional method of SOC analysis (Walkley-Black or dry combustion) would result in an expensive, time-consuming and waste generation $\sim 600,000 \mathrm{~L} /$ year in Brazil [5]; consequently, restricts their use on a large scale [5,7].

This procedure is very contradictory, since on the one hand the GHG emissions could be mitigated by the adoption of the ABC Plan, on the other hand more pollution could be generated by increasing demand for SOC analysis that would negatively impact the environment. All these factors could eventually restrict the implementation of ABC Plan, requiring drastic changes in the methodologies for SOC analysis.

The implementation of near infrared spectroscopy (NIRS) technologies could become an effective solution to overcome these methodological issues that have been blocking the ABC Plan from reaching the next level. Several papers and documents that have been published over the last decade, such as those produced by FAO [8], recommend the use NIRS for SOC analysis [9-12]. 
In a previous study, de Santana and collaborators [5] compared the accuracy and precision in SOM determinations by the Walkley-Black and NIR methodology using a vast vis-NIR soil spectral library ( 43,000 samples). The methodology developed was validated by a proficiency assay for fertility laboratories coordinated by Embrapa soils (Brazilian Agricultural Research Corporation). The results obtained shows that the vis-NIR spectroscopy can determinate the SOM content in Brazilian soils with the same accuracy and precision than the Walkley-Black method [5]. It is important to highlight that the SOC analysis was performed on the total fraction of the sample (bulk soil).

In other study, Jaconi and collaborators [12] evaluated and optimized the use of NIRS to predict SOC content in fractions with the constraint that the carbon fractions (labile and stabilized) should add up to $100 \%$ (total organic carbon content). Through employing log-ratio transformation, it was demonstrated that the NIRS models could be suitable to predict soil carbon fractions with high accuracy in a wide range of soil types and land-use types.

Following the studies developed by the group, the present study aims to contribute to the discussion regarding analytical methodology to quantify the most stable fraction of SOC, contributing to the implementation of $A B C$ Plan. In this paper we proposed an effective, fast, cheap, and sustainable methodology without extra sample preparation to quantify the mineral associated $C$ content in soils under sustainable management employing NIRS and partial least squares regression (PLSR). In addition, another innovation of this article is the use of different strategies to improve the SOC stabilized determinations from the NIR spectra of bulk soil.

\section{MATERIAL AND METHODS \\ Study site}

The experimental area is in a thematic center of Embrapa (Brazilian Agricultural Research Corporation, Embrapa), Embrapa Dairy Cattle, Coronel Pacheco's Municipality, Minas Gerais State, Brazil, (2133'22"S, $43^{\circ} 06^{\prime} 16^{\prime \prime} \mathrm{W}$, an altitude of $410 \mathrm{~m}$ ). According to the Köppen climate classification, the region fits the Cwa type (mesothermal), with a well-defined dry season (autumn-winter) and rainy season (spring-summer) [13]. Annual rainfall (average of 30 years) is around $1,600 \mathrm{~mm}$, of which approximately $90 \%$ occurs in the summer season. Annual temperatures varied from 24.3 to $31.7^{\circ} \mathrm{C}$ (maximum) and 11.4 to $19.7^{\circ} \mathrm{C}$ (minimum). The soil class of the experimental area is "Latossolo Vermelho Amarelo distrófico" according to the Brazilian Soil Classification System [14], with a clay texture which corresponds to Typic hapludox according to the Soil Survey Manual [15]. The local relief is characterized by mountainous topography with a slope of approximately $30 \%$.

\section{Land uses and characterization}

A set of 122 samples of four different types of land were collected from (1) silvopastoral system (SPS), (2) managed pasture of Brachiaria decumbens (brachiaria managed pasture -BMP), (3) degraded pasture of brachiaria (BDP), and (4) native vegetation (NV). The SPS was established in November 1997 and it is composed with the tropical perennial grass brachiaria. The tree component of SPS was composed by the species of Eucalyptus grandis Hill ex Maiden, Acacia mangium Willd (acacia) and Mimosa artemisiana Heringer \& Paula (mimosa), all of them planted alternately in the North/South direction (planting row) aiming to prevent surface erosion. In the planted row, seedlings were planted with $3 \mathrm{~m}$ of spacing.

The objective of nitrogen-fixing species (acacia and mimosa) in SPS is to provide shade or shelter to the animals and nitrogen biologically fixed $\left(\mathrm{N}_{2}\right)$ and other nutrients, to the eucalyptus and brachiaria. The BMP maintain reasonable grass productivity due to appropriate grazing regime. The history of the use of correctives and fertilizers used in this area is organized in the Table I. 
Table I. Management history of the Silvopastoral System in Coronel Pacheco - MG

\begin{tabular}{ll}
\hline Year & Management \\
\hline 1997 & $\begin{array}{l}\text { At the moment of the introduction of the trees, the guandu beans (Cajanus cajan) } \\
\text { were planted, among the wooded strips, in order to be incorporated into the soil, as } \\
\text { green manure, before the flowering of the plants. }\end{array}$ \\
$1998-2000 \quad$ & The pastures remained closed to guarantee the initial growth of the tree species. \\
$2001-2002$ & $\begin{array}{l}\text { The pastures were used for the grazing of dry cows, respecting periods of occupation } \\
\text { of } 5 \text { days and resting of } 45 \text { days. }\end{array}$ \\
$2003-2010 \quad \begin{array}{l}\text { The grazing management was carried out under rotational stocking and without } \\
\text { fertilization. }\end{array}$ \\
$\begin{array}{l}\text { Under continuous stocking and with application of } 64 \mathrm{~kg} / \mathrm{ha} \text { of } \mathrm{N} \text { and } \mathrm{K}_{2} \mathrm{O} \text { and } 16 \mathrm{~kg} / \\
\text { ha of } \mathrm{P}_{2} \mathrm{O}_{5} \text { per year, divided into two equal applications during the summer. }\end{array}$ \\
$\begin{array}{l}\text { There were no additional fertilizer or corrective applications, characterized by a low } \\
\text { input and extensive system (low rate of grazing and lenient grazing). By this way we } \\
\text { guarantee the sustainability of the pasture after } 18 \text { years of implantation. }\end{array}$ \\
\hline
\end{tabular}

The DPB was characterized to presents low productivity for animal grazing due to high weed infestation, bare soil and/or soil erosion. The NV belongs to the ecosystem of the Atlantic Forest [16] without any exploitation or anthropic interference at least in the last 40 years.

\section{Soil sampling design}

The soil sampling strategy was designed for two main purposes: soil organic matter physical fractionation and to study the soil $\mathrm{C}$ distribution in the soil profile. As all the systems (SPS, BMP, BDP and NV) were immersed in a mountainous landscape we divided them into three sub-areas considering the slope of the terrain: upper, mid and lower third of the slope.

In the SPS, the tree component has a great influence on soil chemical and physical attributes. To cover these influences, we select three different positions to collect soils samples in SPS: inside the ranks of trees, tree border (under canopy influence) and the middle of two ranks. Under BMP, BDP and NV three and under SPS nine trenches were opened. The soil samples were collected in seven different depths in each area for assessment of $0-10,10-20,20-30,30-40,40-60,60-80$ and $80-100 \mathrm{~cm}$ of soil layers.

\section{Soil sample preparation}

All soil samples were oven dried at $40{ }^{\circ} \mathrm{C}$ for $48 \mathrm{~h}$, then a rubber mallet was used to break the soil clusters, and for the granulometry standardization the soils were sieved using a $2 \mathrm{~mm}$ sieve [6].

\section{Physical fractionation}

The bulk soil samples were physically fractionated according to the procedure of Cambardella \& Elliott (1992) [2] with some adaptations in the sample weight [17]. Briefly, $20 \mathrm{~g}$ of soil were placed in plastic bottles and $60 \mathrm{~mL}$ of $\mathrm{NaOH} 1.0 \mathrm{~g} \mathrm{~L}^{-1}$ was added. The mixture was shaken for $16 \mathrm{~h}$ in a horizontal shaker, at 160 oscillations $\mathrm{min}^{-1}$. Then, the entire content was placed on a $53 \mu \mathrm{m}$ sieve and washed with a weak jet of demineralized water. The material retained on the sieve is defined as particulate organic matter (POM) $(>53 \mu \mathrm{m})$ known as labile fraction; on the other hand, the material that passed the sieve is defined as the mineral-associated organic matter (MOM), also known as stabilized fraction. Both fractions were dried at $60{ }^{\circ} \mathrm{C}$. 


\section{Soil organic carbon analysis}

After the physical fractionation step, the soil samples were grounded to a fine powder $(<0.149 \mathrm{~mm})$ to facilitate the weighing process. The soil organic carbon in both fractions (POM and MOM) and bulk soil (total fraction) was analyzed by the dry combustion method using a CHNS Perkin Elmer 2400.

\section{Acquisition of NIR spectra}

The NIR spectra in reflectance mode were registered using a Perkin Elmer Fourier Transform spectrophotometer, Spectrum $100 \mathrm{~N}$, equipped with integrating sphere and rotation accessory, in the range of $1000-2500 \mathrm{~nm}, 0.5$ of spectral resolution and 64 scans. Before each analysis, the background was obtained using the Spectralon ${ }^{\circledR}$ present in integrating sphere.

\section{Chemometrics analysis}

Spectral preprocessing

In order to reduce the baseline variation and enhance the spectral features, all soil spectra were preprocessed using smoothing and first derivative, based on the Savitzky-Golay algorithm, with a window size of 11 points and second-order polynomial fitting [18].

\section{Principal component analysis}

Principal component analysis (PCA) is a classical data analysis technique, which can compress information from many interconnected variables and project these new variables in a low-dimensional subspace defined by a few principal components (PCs). The original dataset (X) is decomposed in two matrices $\mathbf{P}$ and $\mathbf{T}$ as illustrated in Equation 1. The orthonormal loading matrix $\mathbf{P}$ contain information about the weight of the original variables in the PC space and the orthogonal score matrix $\mathbf{T}$ are the new coordinates of these samples in the PC space.

$$
\mathbf{X}=\mathrm{TP}^{\top}+\mathbf{E} \quad \text { Equation } 1
$$

where $\mathbf{E}$ is the part non-modeled of $\mathbf{X}$ (residual matrix) [19].

\section{Partial least squares regression (PLSR)}

Partial least squares regression (PLSR) is the most widely used calibration method used in quantifications from NIR spectral data [20]. The PLSR performs a multivariate regression using the $\mathbf{X}$ block (NIR spectra) and property of interest $\mathbf{y}$ ( $\mathrm{C}$ in different fractions), by projecting the $\mathbf{X}$ block in a low-dimensional subspace, called latent variable space [21]. To obtain feasible results in validation set, it is necessary correctly choose the number of latent variables and remove the outlier's samples in calibration set [21]. The optimum number of latent variables can be selected analyzing the fewest number of latent variables which present minimal difference in relation to the minimum value of root mean squares errors of cross-validation - RMSECV [22]. In this study, due to the large number of samples, we used the venetian blinds cross-validation [23].

The outliers in calibration step should be evaluated in $\mathbf{X}$ block and $\mathbf{y}$ block, while in validation set the outliers must be evaluate only in $\mathbf{X}$ block. Samples with high Hotelling $\mathrm{T}^{2}$ and residuals in spectral data (Q-statistics) at a significance level of $5 \%$ can be considered outliers in $\mathbf{X}$ block, while in $\mathbf{y}$ block samples with prediction error superior than $\pm 3 \times$ RMSEC (root mean square error in calibration) can be considered outliers. In this last case, it would be interesting to re-analyze the reference values for this sample. The Hotelling $\mathrm{T}^{2}$ value is related to leverage, which measures the distance of the sample from the center of the data, while $Q$ residuals is related to unmodelled NIR spectra. The American Society for Testing and Materials, ASTM E1655-17 [24] recommends that a maximum of 3 rounds should be performed to removes outlier samples in calibration step. 


\section{External parameter orthogonalization (EPO)}

The EPO method aims to remove the effect of external parameters in spectra. In this study we adapted the EPO to remove the labile SOC fraction from the total soil fraction (bulk). The EPO method will remove the labile SOC fraction (POM) from the bulk by projecting the NIR spectra into a portion of spectral space which is orthogonal to POM spectra $[25,26]$.

The EPO method assumes that spectra matrix $\mathbf{X}$ can be decomposed into two subspaces, a useful subspace related to target chemical responses and a parasitic component related to the part of the spectra that is not related to the target chemical responses as illustrated in Equation 2

$$
\mathbf{X}=\mathbf{X U}+\mathbf{X Q}+\mathbf{R} \quad \text { Equation } 2
$$

where $\mathbf{R}$ is an independent residual matrix.

The initial step to build the EPO model is to calculate (labile fraction/POM), which is the difference between the spectra of total and the stabilized fractions (MOM). In the next step, the PCA model is build using and are obtained the scores and the loadings, and using these loadings we can calculate the scores (for new samples (validation samples). By multiplying is obtained, which is the part of the soil spectra related to POM fraction. Considering that is irrelevant, it is possible to calculate the stabilized fraction by subtracting the original spectra from (POM fraction) [27]. Finally, the PLSR model is built using the matrix (spectra of MOM fraction) and the SOC content in MOM fraction.

\section{Strategies to build the PLSR models}

The 122 soil samples (all set) were firstly organized in ascending order of concentration and then for each group of three samples in sequence, the first two were selected to be used in calibration set $(66.67 \%)$ and the remaining one was used in the validation set (33.33\%). Two references PLSR model (Classical strategy) were built, and four different strategies were evaluated to determine the SOC content in MOM fraction from the NIR spectra of bulk soil (total fraction). These strategies were proposed to avoid the extra step regarding to soil fractionation.

The classical strategies to determine SOC content in the bulk soil and MOM fractions were named Model 1 and Model 2 (Figure 1). In the Model 1, the matrix $\left(\mathbf{X}_{1}\right)$ was measured on soil total fraction (bulk). About $67 \%$ of these samples were used in calibration $\left(\mathbf{X}_{\text {cal1 }}\right)$ and $33 \%$ of these samples were used in validation $\left(\mathbf{X}_{\text {val1 }}\right)$. Reference values $\left(\mathbf{Y}_{\text {cal1 }}\right.$ and $\left.\mathbf{Y}_{\text {val1 }}\right)$ were the SOC measured in the soil total fraction. In the Model 2, the matrix $\left(\mathbf{X}_{2}\right)$ was measured on MOM fraction. Again about $67 \%$ of these samples were used in calibration $\left(\mathbf{X}_{\mathrm{cal} 2}\right)$ and $33 \%$ of these samples were used in validation $\left(\mathbf{X}_{\mathrm{val} 2}\right)$. Reference values $\left(\mathbf{Y}_{\mathrm{cal2}}\right.$ and $\mathbf{Y}_{\text {val2 }}$ ) was the SOC measured in the MOM fraction.

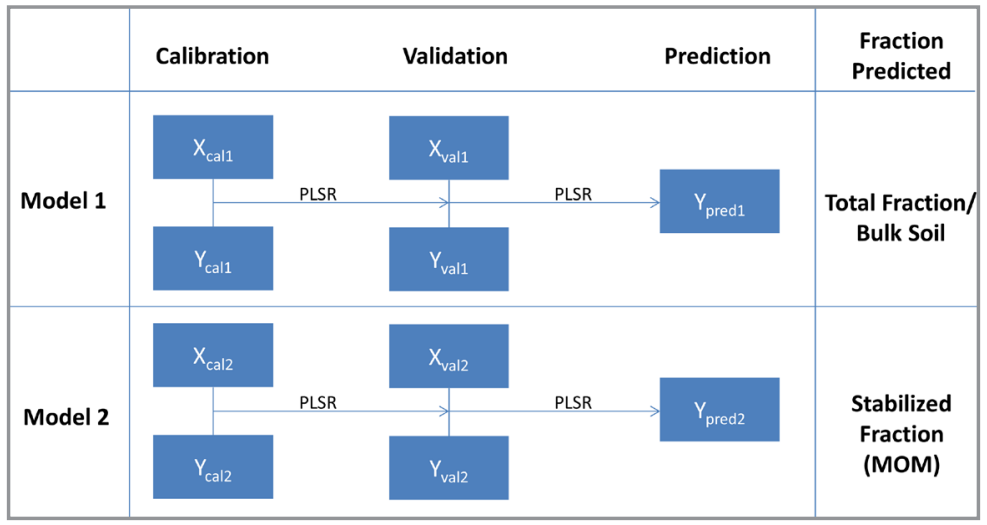

Figure 1. Classical strategy to build PLS models in both subsets: total and stabilized fractions. 
The four strategies evaluated here to determine the SOC content in MOM fraction $\left(\mathbf{Y}_{2}\right)$ from the bulk soil spectra $\left(\mathbf{X}_{1}\right)$ were named Model 3, Model 4, Model 5, and Model 6, as represented in Figure 2. In the Model 3, the calibration samples $\left(\mathbf{X}_{\text {ca11 }}\right.$ and $\left.\mathbf{Y}_{\text {cal1 }}\right)$ were the spectra measured on soil total fraction and the SOC measured in the soil total fraction, in other words is the calibration of Model 1 . While the validation samples $\left(\mathbf{X}_{\text {val2 }}\right.$ and $\mathbf{Y}_{\text {val2 }}$ ) were spectra measured on MOM fraction and the SOC measured in the MOM fraction, that is the validation of Model 2.

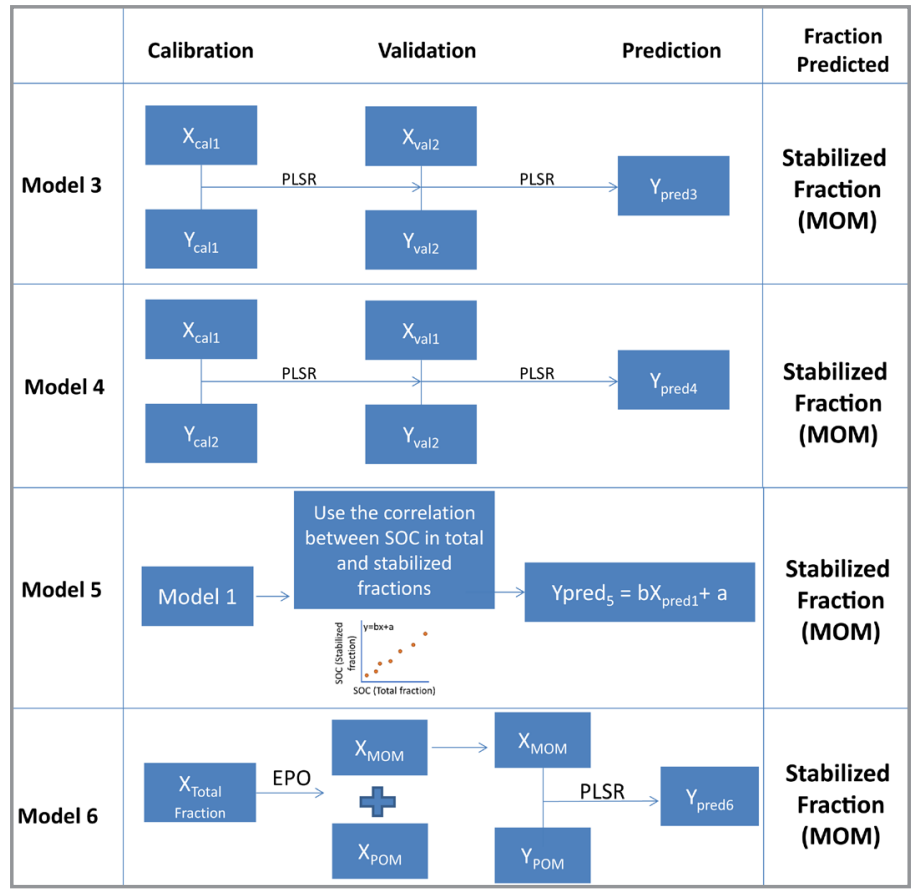

Figure 2. Strategies adopted to determine the SOM content in the MOM fraction from the bulk soil spectra.

In Model 4, the calibration dataset was composed by the spectral data set $\mathbf{X}_{\text {cal1 }}$ (obtained on soil total fraction) and the $Y_{\text {cal2 }}$ (SOC measured in the MOM fraction), the validation dataset is formed by the same logic, using $\mathbf{X}_{\text {val1 }}$ and $\mathbf{Y}_{\text {val2. }}$. The predicted value, $\mathbf{Y}_{\text {pred4 }}$, correspond to the SOC content in MOM fraction.

In Model 5, it was used the Model 1 to determine $\mathbf{Y}_{\text {pred1 }}$, and then, a linear correlation between the reference values of stabilized $\mathbf{Y}_{\text {cal2 }}$ and total soil organic carbon $\mathbf{Y}_{\text {cal1 }}$ were used to determine $\mathbf{Y}_{\text {pred5}}$, which is the SOC in MOM fraction. Finally, in the Model 6, it was used the EPO methodology to decompose the $\mathbf{X}_{\text {Total fraction }}$ in to $\mathbf{X}_{\mathrm{MOM}}$ and $\mathbf{X}_{\mathrm{POM}}$, then it was used the $\mathbf{X}_{\mathrm{MOM}}$ fraction to build the PLSR model. To build the EPO model, about $30 \%$ of the calibration samples were used.

\section{RESULTS AND DISCUSSION}

The average of the NIR spectra of the total, POM and MOM fractions of soil are shown in Figure 3. It is possible to observe that the spectra of total and MOM fractions are very similar, while the spectra of POM fraction are very different due to majority presence of sand [28]. The spectra of total and MOM fractions show essentially absorptions at 1200-1500, 1800-2000 and 2200-2400 nm, common to most soil NIR spectra already reported in several publications $[5,28]$. The NIR spectra contain fewer absorptions bands when compared to MIR spectroscopy, due to the broad and overlapping bands, making it difficult to interpret. However, NIR spectra are influenced by the information of organic and inorganic components present in the soil, including SOC content. 


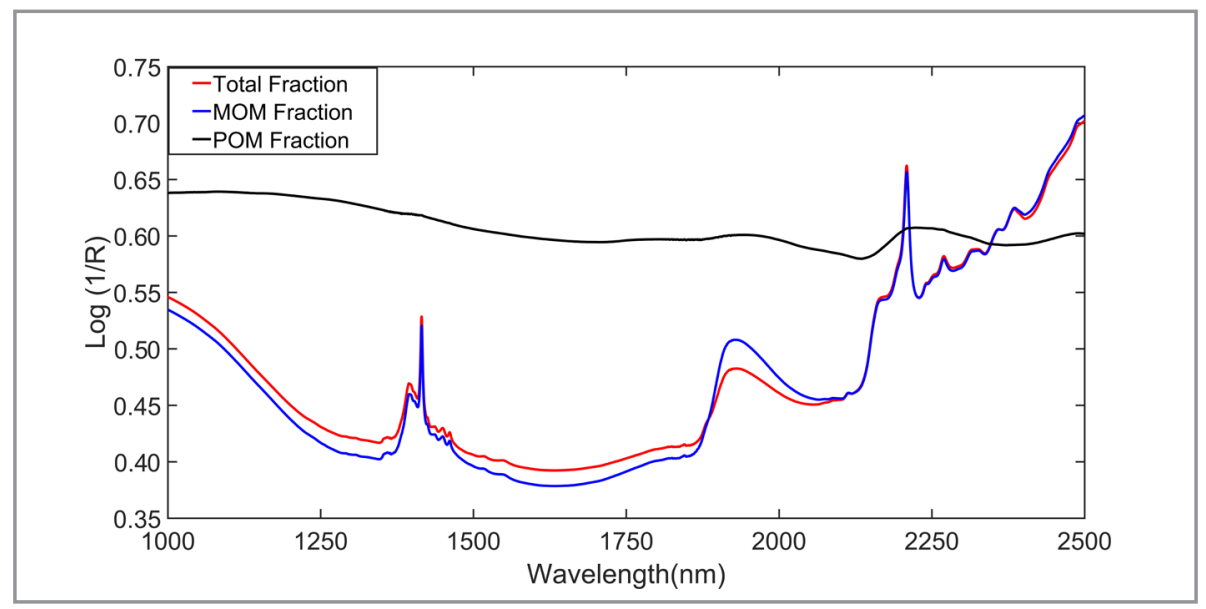

Figure 3. NIR spectra of total, MOM and POM fractions.

A visual inspection along the full spectrum suggests that there is no difference in the NIR spectra of the total and MOM fractions, but a refined comparation between these 3 fractions can be performed through the analysis of scores values of PCA [20]. The scores values of PCA are presented in Figure 4, showing a clear differentiation between POM and others fractions along the PC1 axis, while the PC2 shows the difference between the MOM and total fraction.

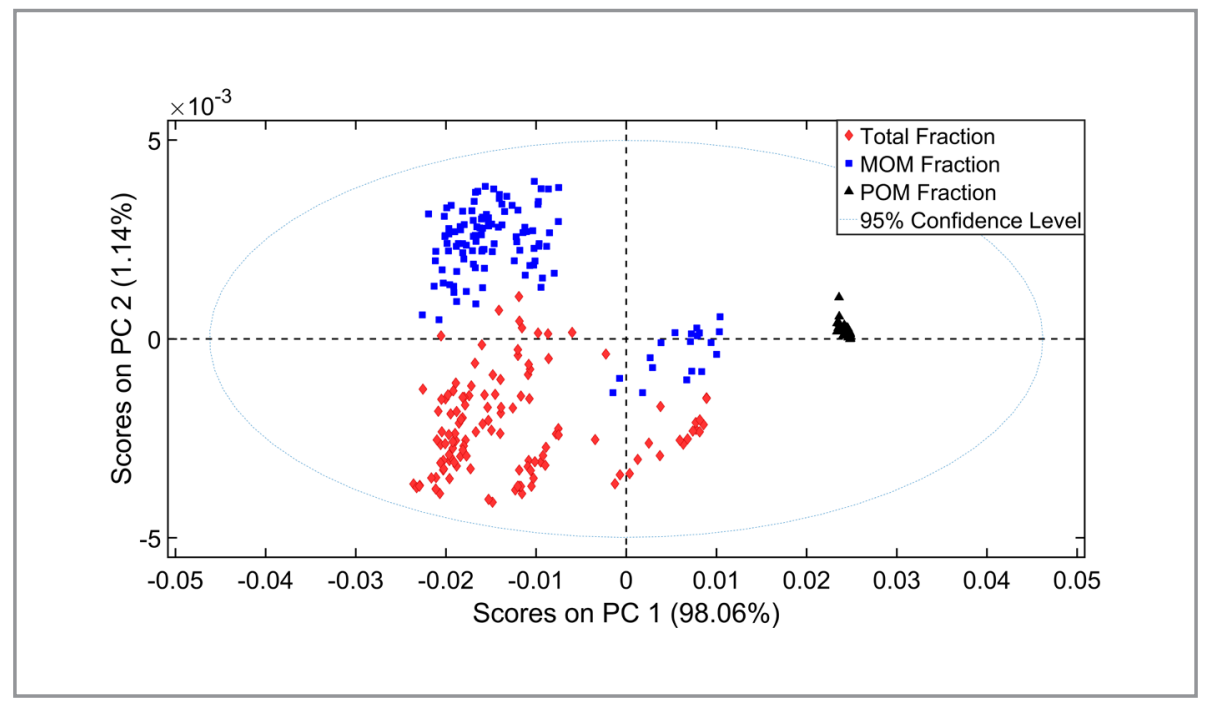

Figure 4. Scores values of PCA from total, MOM and POM soil fractions.

The scores of the total and MOM fractions are not grouped, indicating that these spectra are different and consequently a PLSR model build using the NIR spectra of the total fraction is not able to directly determine the content of SOC in MOM fraction. To solve this problem, we used the four strategies previously described, thus eliminating the additional soil fractionation step.

Figure 5 presents the scatter plots showing the reference versus predicted values by each strategy proposed (Models 1 to 6), the accuracy parameters and the number of outliers samples obtained for each model are organized in Table II. The efficiency in determine the stabilized SOC by each strategy will be compared to the PLSR model build using the NIR spectra of stabilized fraction and the SOC content in this fraction (Model 2). 


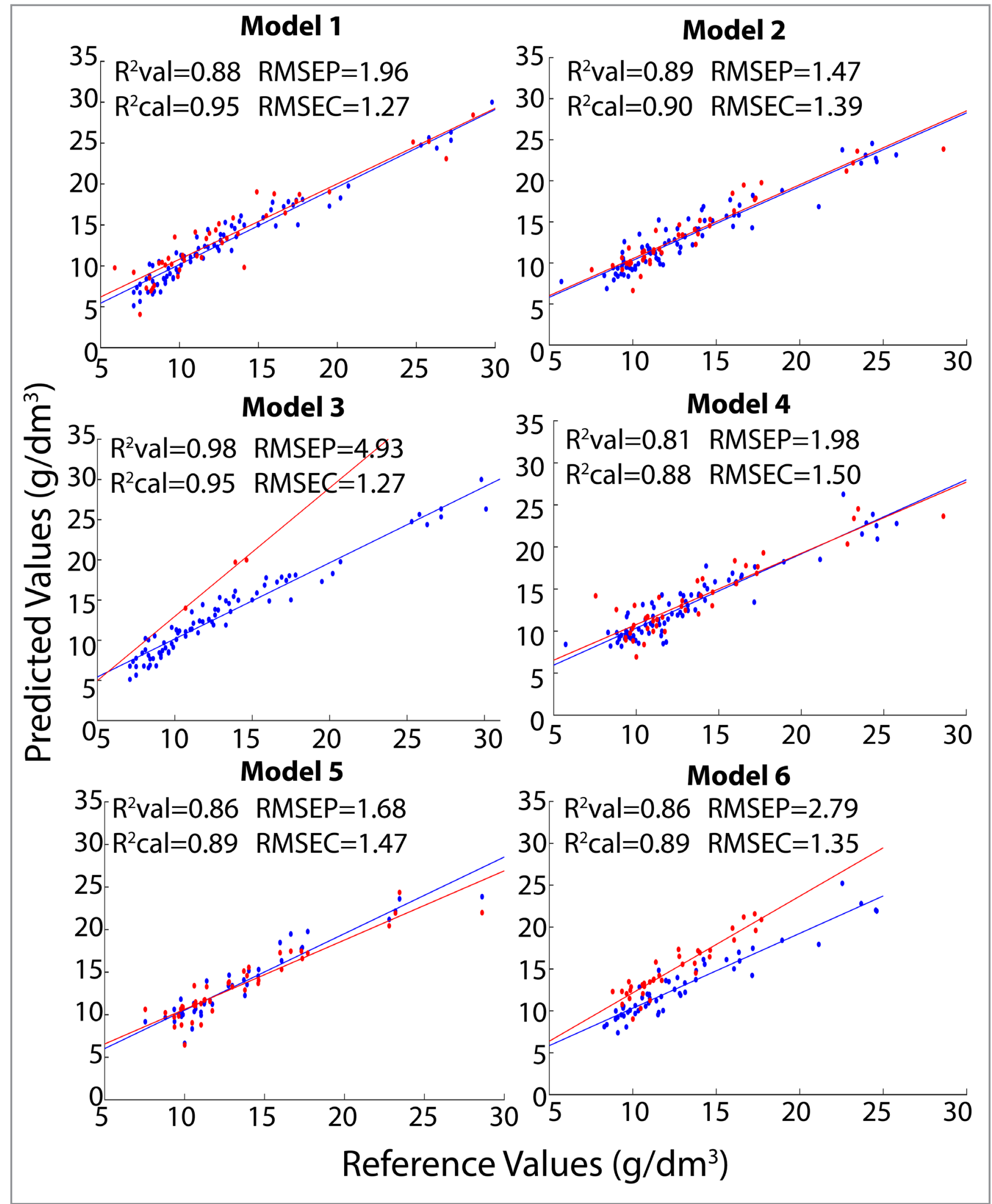

Figure 5. Scatter plots of reference versus PLSR predict values for each reference model and all strategies proposed. 
Table II. Accuracy parameters and excluded samples for the strategies proposed

\begin{tabular}{llcccc}
\hline Strategy & Calibration & $\begin{array}{c}\text { No. of } \\
\text { samples }\end{array}$ & RMSE $\left(\mathbf{g} / \mathbf{d m}^{3}\right)$ & $\mathbf{R}^{2}$ & $\begin{array}{c}\text { No. excluded } \\
\text { samples }\end{array}$ \\
\hline \multirow{2}{*}{ Model 1 } & 81 & 1.27 & 0.95 & 1 \\
& Validation & 41 & 1.96 & 0.88 & 0 \\
\hline \multirow{2}{*}{ Model 2 } & Calibration & 81 & 1.39 & 0.90 & 1 \\
& Validation & 41 & 1.47 & 0.89 & 0 \\
\hline \multirow{2}{*}{ Model 3 } & Calibration & 81 & 1.27 & 0.95 & 1 \\
\hline \multirow{2}{*}{ Model 4 } & Validation & 41 & - & - & 38 \\
\hline \multirow{2}{*}{ Model 5 } & Calibration & 81 & 1.50 & 0.88 & 1 \\
& Validation & 41 & 1.98 & 0.81 & 1 \\
\hline \multirow{2}{*}{ Model 6 } & Calibration & 81 & 1.47 & 0.89 & 1 \\
& Validation & 41 & 1.68 & 0.86 & 0 \\
\hline
\end{tabular}

It is observed that the strategy Model 3 shows a poor performance since 38 of the 41 validation samples were considered outliers by the PLSR model. This result was already expected, because as observed by the PCA scores of Figure 4, the spectra of SOC in MOM fractions are significantly different, resulting in outlier samples.

The strategies Model 4 and Model 5 presented slopes of the calibration (blue) and validation (red) lines equivalent, as well as the values of RMSEC and RMSEP, indicating a good concordance between the calibration and validation sets. Also, these two strategies showed results very similar to the Model 2, reference model to determine the stabilized fraction. The Model 6 presented the RMSEP value almost twice times higher than Model 2, indicating lower accuracy compared to the reference model.

However, it is noteworthy that the comparison of the regression models should not be based only in a visual inspection on the scatter plots of reference versus predict values and in the accuracy parameters. A statistical test must be applied to verify if there are significant differences between the strategies proposed (Models 3 to 6) and the reference model (Model 2).

Many authors compare the regression models using an F-test, this test consisted in divided the RMSEP by RMSEP ${ }_{B}$ and then compare the value with an F-distribution (Fisher-Snedecor distribution) with $n_{A}$ and $n_{B}$ degrees of freedom [29]. However, this test is conservative, requiring the independence of prediction errors between models, which cannot be guaranteed since in general we can have tendency (positive or negative) in both models. By this way, in this study we used the randomization test suggested by $\mathrm{H}$. van der Voet [29], to compare the errors (based on RMSEP) in the determinations of the stabilized SOC by each strategy in the validation set. The main advantage of this test is that assumptions about normality or homoscedasticity of the data are not required (distribution-free). A MATLAB code for applying the randomization test in binary comparations can be found in [30], more details about this test can be found in $[29,30]$.

The randomization test was performed by binary comparisons between each strategy proposed and the reference model - Model 2. There is no reason to compare the strategy Model 3 with the reference calibration model, since more than $90 \%$ of the samples were excluded from the validation 
set, thus only 3 binary comparisons were performed. The randomization test was carried out with a significance level of probability of 0.05 , the null $\left(\mathrm{H}_{0}\right)$ and alternative $\left(\mathrm{H}_{1}\right)$ hypothesis evaluated were:

$$
\begin{aligned}
& H_{0}: \operatorname{RMSEP}_{\text {strategy }}=\operatorname{RMSEP}_{\text {Reference calibration model }}(\text { accuracy is equal); } \\
& \mathrm{H}_{1}: \operatorname{RMSEP}_{\text {strategy }} \neq \operatorname{RMSEP}_{\text {Reference calibration model }}(\text { accuracy is not equal). }
\end{aligned}
$$

The results obtained for each randomization test are organized in Table III. The strategies Model 4 and Model 5 used to determine the stabilized SOC from the NIR spectra of total fraction shows the same predictive accuracy ( $p$-value $>0.05$ ) to the reference PLSR model built using the NIR spectra of MOM fraction. In other words, the strategies Model 4 and Model 5 are able to determine stabilized SOM from the NIR spectra of bulk soils with the same accuracy of the reference model, thus eliminating the extra step regarding soil fractionation to determine the stabilized SOC. It is worth mentioning that the Model 6, which uses the EPO method to remove the liable fraction from the total soil fraction spectra, did not present results as good as the reference model, however it is observed that this strategy was able to minimize the prediction errors in stabilized SOC from the NIR spectra of total soil fraction.

Table III. p-values of randomization t-test for all binary comparations

\begin{tabular}{lc}
\hline Binary comparation & p-value for validation set \\
\hline Model 4 x Model 2 & 0.12 \\
Model 5 x Model 2 & 0.38 \\
Model 6 x Model 2 & $1 \times 10^{-5}$ \\
\hline
\end{tabular}

\section{CONCLUSIONS}

This study presented four different strategies to determine the stabilized SOC content using the NIR spectra of total soil fraction (bulk soil) and multivariate calibration model based on PLSR. Among the four strategies proposed two of them (Models 4 and 5) could determine the stabilized SOC content with the same accuracy of the PLSR reference model, thereby eliminating the extra soil fractionation step that is essential to the monitoring of the carbon sequestration potential by agroecosystems that adopt ABC Plan technologies.

Based on the results obtained and all the advantages reported in this study, this environmentally friendly methodology can contribute for the implementation of the National Plan for Low Carbon Emission in Agriculture (ABC Plan), since the methodology could reduce the cost, time required, and wastes generated in SOC determinations.

\section{In Memoriam}

On the $25^{\text {th }}$ of April, 2020, prof. Ronei Jesus Poppi passed away having the same destiny as millions of people who have lost their lives along the sanitarian crisis that afflicted the world. Ronei was a good friend, a shy and sweet person who was always surrounded by his students. His influence is felt on the field he has devoted his career. He will be sorely missed by his family, friends and the worldwide scientific community.

\section{Conflicts of interest}

There are no conflicts to declare. 


\section{Acknowledgements}

The authors thank "Instituto Nacional de Ciência e Tecnologia de Bioanalítica" (INCTBio), "Conselho Nacional de Desenvolvimento Científico e Tecnológico" CNPq, Brazil, [465389/2014-7; 303994/20177; 307434/2020-6], "Coordenação de Aperfeiçoamento de Pessoal de Nível Superior" (CAPES, Brazil, Finance Code 001) and "Fundação de Amparo à Pesquisa do Estado de São Paulo" [FAPESP, Brazil, 2014/508673] for financial support.

\section{REFERENCES}

1. Ministério daAgricultura, Pecuária eAbastecimento. Plano Setorial de Mitigação eAdaptação às Mudanças Climáticas para Consolidação da Economia de Baixa Emissão de Carbono na Agricultura - PLANO $A B C$. Brasília: MAPA/ACS, 2012. Available at: http://www.agricultura.gov.br/assuntos/sustentabilidade/ plano-abc/plano-abc-agricultura-de-baixa-emissao-de-carbono [Accessed 16 January 2021].

2. Cambardella, C. A.; Elliott, E. T. Soil Sci. Soc. Am. J., 1992, 56, pp 1-777 (https://doi.org/10.2136/ sssaj1992.03615995005600030017x).

3. Roscoe, R.; Machado, P. L. O. de A. Fracionamento Físico do Solo em Estudos da Matéria Orgânica. Embrapa agropecuária Oeste, Dourados, MS, 2002.

4. Feller, C.; Beare, M. H. Geoderma, 1997, 79, pp 69-116 (https://doi.org/10.1016/S0016-7061(97)00039-6).

5. de Santana, F. B.; de Souza, A. M.; Poppi, R. J. Sci. Total Environ., 2019, 658, pp 895-900 (https://doi. org/10.1016/j.scitotenv.2018.12.263).

6. Teixeira, P. C.; Donagemma, G. K.; Fontana, A. I.; Teixeira, W. G. Manual de métodos de analise de solo. Embrapa, Brasília, 2017. Available at: https://ainfo.cnptia.embrapa.br/digital/bitstream/item/181717/1/ Manual-de-Metodos-de-Analise-de-Solo-2017.pdf [Accessed 16 January 2021].

7. Rossel, R. A. V.; Hicks, W. S. Eur. J. Soil Sci., 2015, 66, pp 438-450 (https://doi.org/10.1111/ejss.12237).

8. Lefèvre, C.; Rekik, F.; Alcantara, V.; Wiese, L. Soil Organic Carbon: the hidden potential. Food and Agriculture Organization (FAO). Rome, 2017. Available at: http://www.fao.org/3/i6937e/i6937e.pdf [Accessed 16 January 2021].

9. de Santana, F. B.; de Souza, A. M.; Poppi, R. J. Spectrochim. Acta - Part A Mol. Biomol. Spectrosc., 2018, 191, pp 454-462 (https://doi.org/10.1016/j.saa.2017.10.052).

10. Stenberg, B.; Rossel, R. A. V.; Mouazen, A. M.; Wetterlind, J.; Mouazen, M.; Wetterlind, J. Adv. Agron., 2010, 107, pp 163-215 (https://doi.org/10.1016/S0065-2113(10)07005-7).

11. Rossel, R. A. V.; Behrens, T.; Ben-Dor, E.; Brown, D. J.; Demattê, J. A. M.; Shepherd, K. D.; Shi, Z.; Stenberg, B.; Stevens, A.; Adamchuk, V.; et al. Earth-Science Rev., 2016, 155, pp 198-230 (https://doi. org/10.1016/j.earscirev.2016.01.012).

12. Jaconi, A.; Poeplau, C.; Ramirez-Lopez, L.; Van Wesemael, B.; Don, A. Eur. J. Soil Sci., 2019, 70, pp 127-139 (https://doi.org/10.1111/ejss.12761).

13. Alvares, C. A.; Stape, J. L.; Sentelhas, P. C.; De Moraes Gonçalves, J. L.; Sparovek, G. Meteorol. Zeitschrift, 2013, 22, pp 711-728 (https://doi.org/10.1127/0941-2948/2013/0507).

14. EMBRAPA Sistema brasileiro de classificação de solos; Solos, E., Ed.; 5th ed.; Rio de Janeiro - Brasil, 2018.

15. United States Department of Agriculture (USDA), Natural Resources Conservation Service. Keys to soil taxonomy, 12 ${ }^{\text {th }}$ Ed., Washington, 2014. Available at: https://www.nrcs.usda.gov/wps/portal/nrcs/ detail/soils/survey/class/taxonomy/?cid=nrcs142p2_053580 [Accessed 16 January 2021].

16. Ab'Sáber, A. N. Domínios morfoclimáticos e províncias fitogeográficas do Brasil. "Departamento de Geografia, Universidade de São Paulo", 1967.

17. Bongiovanni, M. D.; Lobartini, J. C. Geoderma, 2006, 136, pp 660-665 (https://doi.org/10.1016/j. geoderma.2006.05.002).

18. Savitzky, A.; Golay, M. J. E. Anal. Chem., 1964, 36, pp 1627-1639 (https://doi.org/10.1021/ac60214a047). 19. Bro, R.; Smilde, A. K. Anal. Methods, 2014, 6, pp 2812-2831 (https://doi.org/10.1039/c3ay41907j).

20. Pasquini, C. Anal. Chim. Acta, 2018, 1026, pp 8-36 (https://doi.org/10.1016/j.aca.2018.04.004). 
21. Geladi, P.; Kowalski, B. R. Anal. Chim. Acta, 1986, 185, pp 1-17 (https://doi.org/10.1016/00032670(86)80028-9).

22. Haaland, D. M.; Thomas, E. V. Anal. Chem., 1988, 60, pp 1193-1202 (https://doi.org/10.1021/ ac00162a020).

23. Westad, F.; Marini, F. Anal. Chim. Acta, 2015, 893, pp 14-24 (https://doi.org/10.1016/j.aca.2015.06.056).

24. American Society for Testing Materials. ASTM E1655-17. Standard Practices for Infrared Multivariate Quantitative Analysis. West Conshohocken, PA, US, 2017.

25. Roger, J. M.; Chauchard, F.; Bellon-Maurel, V. Chemom. Intell. Lab. Syst., 2003, 66, pp 191-204 (https://doi.org/10.1016/S0169-7439(03)00051-0).

26. de Santana, F. B.; de Giuseppe, L. O.; de Souza, A. M.; Poppi, R. J. Microchem. J., 2019, 145, pp 1094-1101 (https://doi.org/10.1016/j.microc.2018.12.027).

27. Minasny, B.; McBratney, A. B.; Bellon-Maurel, V.; Roger, J. M.; Gobrecht, A.; Ferrand, L.; Joalland, S. Geoderma, 2011, 167-168, pp 118-124 (https://doi.org/10.1016/j.geoderma.2011.09.008).

28. Stenberg, B.; Rossel, R. A. V.; Mouazen, M.; Wetterlind, J. Adv. Agron., 2010, 107, pp 163-215 (https:// doi.org/10.1016/s0065-2113(10)07005-7).

29. van der Voet, H. Chemom. Intell. Lab. Syst., 1994, 25, pp 313-323 (https://doi.org/10.1016/01697439(94)85050-X).

30. Olivieri, A. C. Anal. Chim. Acta, 2015, 868, pp 10-22 (https://doi.org/10.1016/j.aca.2015.01.017). 